\title{
Retailer attitudes on tobacco sales to minors in New South Wales, Australia
}

\author{
Margot J Schofield, Sally Gulliver, Rob W Sanson-Fisher
}

\begin{abstract}
Objective - To investigate retailer knowledge of the law governing tobacco sales to minors, their attitudes toward the law, and their self reported retail practices following a change in the law in New South Wales, Australia.

Methods-A telephone survey of 241 tobacco retailers in the lower Hunter region of New South Wales in 1992, nine months after enactment of a new state law raising the legal age for selling tobacco to 18 years and increasing fines to retailers for breaches of the law.

Results - Knowledge of the new law was high, with $94 \%$ of retailers knowing the correct legal age for sales, and $65 \%$ knowing the amount of the fine for selling tobacco to minors. Despite retailer perceptions of a high level of sales to minors, the perceived likelihood of enforcement and prosecution of the law were low. More than half the retailers thought that it was acceptable to sell tobacco to minors under certain conditions.

Conclusions-While knowledge of the tobacco sales to minors law is high among retailers in NSW, considerable work is needed to encourage attitudes among retailers which are more supportive of smoking control initiatives, particularly with regard to adolescent smoking.
\end{abstract}

(Tobacco Control 1995; 4: 362-366)

Keywords: tobacco sales; minors; legal sanctions; retailers

\section{Introduction}

Despite mounting evidence of the deleterious health effects of smoking, smoking rates among Australian adolescents are still unacceptably high. ${ }^{1.2}$ A recent study among Australian secondary school students found the prevalence of smoking among 16 year old boys to be $25 \%$ and among 15 year old girls $29 \%$, comparable with adult smoking rates. ${ }^{2}$ One reason for high smoking rates among adolescents is likely to be ease of access to cigarettes. Several Australian studies suggest that the law banning the sale of cigarettes to minors, which dates back to 1901 , has not been very effective. A South Australian study showed that children aged between 12 and 14 years had a $50 \%$ success rate for purchasing cigarettes from retail stores, while the success rate for vending machines was $100 \% .^{3}$ Another Australian study found that apparently under- age youth had a success rate of $85 \%$ for purchasing cigarettes from retail stores in New South Wales (NSW) without requiring proof of age. ${ }^{4}$ The extent of illegal sales to minors in NSW was further demonstrated by a survey which found that $38 \%$ of 12 to 15 year olds reported having purchased cigarettes illegally. ${ }^{4}$ International studies report similarly low levels of compliance with legislation banning sales of cigarettes to minors. For instance, a pooled analysis of six international studies showed that minors were successful on $72 \%$ of 852 purchase attempts at retail stores and $100 \%$ of the time at vending machines. ${ }^{5-10}$

Reasons suggested for this poor adherence to the law include poorly drafted legislation, the low cost of tobacco licences, low fines for breaches, and low commitment to enforcement. ${ }^{11,12}$ For instance, in NSW there is no history of prosecution against retailers for the illegal sale of cigarettes to minors. ${ }^{13}$ Health activists have argued strongly for increasing the age of youth who can purchase cigarettes legally, greater enforcement of the sales legislation, and an increase in education of retailers about their responsibilities under the law. ${ }^{12-14}$ Studies from the United States and Britain have shown that interventions to educate retailers can effect a short term reduction in the sale of cigarettes to minors, ${ }^{15}$ but are far more effective when combined with active enforcement through consistent compliance checks. ${ }^{8.16-18}$ Reductions of up to $50 \%$ in sales to minors can be achieved using this approach. ${ }^{17,18}$

Over the past 30 years, the Australian government, like many western governments, has responded to this public health problem by introducing a range of policy and legislative strategies aimed at reducing the appeal of and access to tobacco and thus the prevalence of smoking in the community. ${ }^{19.20}$ These include the introduction of health hazard warnings on cigarette packaging, the development and promotion of antismoking campaigns in the media and schools, increasing the tax on cigarettes, and in 1991 bans on most forms of tobacco advertising. ${ }^{20,21}$ An amendment to the 1901 Public Health (Tobacco) Act in New South Wales in 1991 raised the legal age of young people who could be sold tobacco products from 16 to 18 years and increased the fines for retailers who breach the law from $\$ 2000$ to $\$ 5000 .^{22}$

The intent of the revised NSW Public Health Act was to ensure greater restriction of minors' access to tobacco. At the time the new 
legislation became active, the state health departments sent letters to all tobacco retailers advising them of the new legislation, and there were several media reports on the legislation. Copies of the warning signs which retailers are required by law to display were also sent to all retailers. Public health officers employed within the public health units of the state health departments and the police were given powers to prosecute offending retailers; however, at the time of the study there were no apparent special enforcement initiatives. Furthermore, there was a general perception among public health officers that legislation was difficult to enforce.

The actual effectiveness of the revised legislation is yet to be established, although a study in rural NSW has shown that more than $50 \%$ of retailers in one region alone were still selling cigarettes to underage teenagers eight to 14 months after the laws were amended..$^{23} \mathrm{~A}$ similar study in Western Australia following the introduction of revised legislation found that despite $75 \%$ of retailers claiming to support the new legislation, $89 \%$ of purchase attempts by apparently underage adolescents were successful. ${ }^{24}$ The successful implementation of the law arguably relies on the knowledge and attitudes of retailers as well as on their motivation and commitment to adhere to the law.

In this study we aimed to examine retailers' knowledge of the new law, their attitudes toward the law, and their self reported practice of the law. The study also aimed to determine whether retailer knowledge and attitudes differed by size and type of store. Such information about retailer knowledge, attitudes, and practices is valuable in helping to design successful interventions to reduce sales to minors.

\section{Methods \\ SAMPLE \\ Three hundred retail outlets which commonly sell tobacco products were randomly selected, using a list of random numbers, from the telephone business listings in the lower Hunter region of New South Wales, Australia, with a population of approximately 500000 . This represented approximately $90 \%$ of stores listed in the telephone directory. The outlets included service stations, newsagents, super- markets and grocery stores, take away food stores, and tobacconists.}

\section{PROCEDURE}

A telephone survey of the managers and owners of selected outlets was conducted in August 1992 by trained telephone interviewers. Retailers who could not be contacted by phone were visited and asked to complete the questionnaire. The survey covered: (a) store characteristics, such as number of employees; (b) knowledge of the new law, such as the legal age at which tobacco can be sold and the level of fines for selling to minors; (c) attitudes toward the law, such as what they think should be the legal age limit, whether they think the law can be enforced, their perceptions of the extent to which the law is observed and enforced in their area, and their perceptions of the effectiveness of various named smoking control measures; (d) their self reported practice of the new law such as the conditions under which they think it is acceptable to sell cigarettes to minors, what they do if they have doubts about the buyer's age, and whether they have trained their staff to prevent sales to minors.

\section{Results}

SAMPLE CHARACTERISTICS

Of the 300 retail outlets, 19 were found to be ineligible for the study because they did not sell tobacco, did not speak English, had closed down, or were duplicated listings. Of the remaining 281 outlets, $241(86 \%)$ completed the interview. The sample included 20 supermarkets $(8 \%), 107$ takeaway food stores $(44 \%), 47$ newsagents $(20 \%), 10$ tobacconists $(4 \%)$, and 57 service stations/garages $(24 \%)$. Six $(3 \%)$ stores had no employees other than the owner/manager, $163(69 \%)$ had $1-5 \mathrm{em}-$ ployees, $48(20 \%)$ had 6-10 employees, and 18 $(8 \%)$ had more than 10 employees.

\section{RETAILER KNOWLEDGE OF THE LAW}

A total of $225(94 \%)$ retailers correctly stated the legal age for sales of cigarettes as 18 years. Only $143(65 \%)$ retailers knew that the new penalty for underage sales was $\$ 5000$.

\section{RETAILER ATTITUDES TOWARDS THE NEW LAW Age limit for sales}

A total of 131 retailers $(58 \%$ ) thought that 18 years should be the legal age for sales of cigarettes, $62(27 \%)$ thought it should be less than 18 years, and $35(15 \%)$ thought it should be more than 18 years.

Adherence to and enforceability of the law Only 102 retailers ( $43 \%$ ) thought that the new legislation was able to be enforced. Retailers believed that prosecutions were most likely to occur by parental reporting $(37 \%)$, by a public health inspector observing the sale $(27 \%)$, or by police observing a sale $(10 \%)$, or by some other way $(26 \%)$.

\section{Adherence to the law by local retailers}

Fifty nine percent of retailers thought that cigarettes were knowingly sold to underage youth by some retailers in their area. Despite this perception of a high rate of illegal sales, only $18 \%$ thought that retailers in their area were likely to get reported in the next 12 months, $13 \%$ thought that retailers in their areas were likely to get prosecuted, whereas $50 \%$ thought that some retailers should get prosecuted. 
Table 1 Retailer perceptions of the effectiveness of smoking control strategies

Percentage of retailers who agreed that the following measures would be fairly to extremely effective in restricting the availability of cigarettes to young people $(N=236)$

Type of smoking control strategy

\begin{tabular}{ll}
\hline$n$ & $\%$ \\
\hline 96 & 41 \\
88 & 37 \\
80 & 34 \\
72 & 31 \\
68 & 29 \\
57 & 24 \\
56 & 24 \\
49 & 21 \\
49 & 21 \\
29 & 12 \\
26 & 11
\end{tabular}

Restrict placement of vending machines Stricter enforcement of laws

Ban smoking in public

Ban smoking completely (ie, total prohibition)

Decrease places to smoke

Ban vending machine

Ban advertisements appealing to the young

Ban all cigarette advertising

Increase taxes so less affordable to the young

Increase the minimum number of cigarettes per pack

Increase size of health warnings on cigarette packs

\section{Characteristics of illegal sales}

While 107 retailers ( $45 \%$ ) thought that underage buying of cigarettes was equally likely to occur for boys and girls, $86(36 \%)$ thought that underage girls were more likely to buy than boys, and $45(19 \%)$ thought boys who were underage were more likely to buy than girls. Retailers believed that the easiest venues for those under age 18 to buy cigarettes were: vending machine $(33 \%)$, general store $(20 \%)$, petrol station (18\%), supermarket $(12 \%)$, milk bar (cafe or snack bar) $(7 \%)$, other $(10 \%)$.

\section{Likely effectiveness of smoking control strategies}

Retailers were asked how effective they thought a range of smoking control strategies would be in restricting the availability of tobacco to young people. The percentage of retailers who thought that these strategies would be fairly to extremely effective is shown in table 1 . More than $30 \%$ of retailers thought the following strategies would be effective in limiting the availability of tobacco to underage children: restricting placement of vending machines or banning them altogether; having stricter enforcement of the laws; banning smoking in public places; and banning smoking completely (that is, total prohibition).

Table 2 Relation between type of store and retailer knowledge, attitudes, and self reported sales practices

\begin{tabular}{|c|c|c|c|c|c|c|}
\hline & \multicolumn{2}{|c|}{$\begin{array}{l}\text { Supermarkets } \\
\quad(n=20)\end{array}$} & \multicolumn{2}{|c|}{$\begin{array}{c}\text { General } \\
\text { stores } \\
(n=107)\end{array}$} & \multicolumn{2}{|c|}{$\begin{array}{c}\text { Specialist } \\
\text { stores } \\
(n=103)\end{array}$} \\
\hline & $n$ & $\%$ & $n$ & $\%$ & $n$ & $\%$ \\
\hline \multicolumn{7}{|l|}{ Knowledge } \\
\hline $\begin{array}{l}\text { Knew legal age } \\
\text { Knew maximum fine }\end{array}$ & 18 & 90 & 99 & 93 & 102 & $99 \star$ \\
\hline Knew maximum fine & 16 & 80 & 85 & 79 & 63 & $61 \dagger$ \\
\hline \multicolumn{7}{|l|}{ Attitudes } \\
\hline Agreed with 18 years limit & 7 & 35 & 52 & 49 & 67 & $64+$ \\
\hline Believed legislation enforceable & 8 & 40 & 51 & 49 & 39 & 38 \\
\hline Believed retailers sold to minors & 11 & 61 & 55 & 60 & 56 & 58 \\
\hline Believed retailers likely to get reported & 3 & 17 & 19 & 21 & 16 & 16 \\
\hline Believed retailers should be prosecuted & 11 & 61 & 48 & 53 & 43 & 44 \\
\hline Believed stricter enforcement would work & 11 & 55 & 29 & 28 & 43 & $43^{\star}$ \\
\hline $\begin{array}{l}\text { Believed cigarettes more likely than } \\
\text { alcohol to lead to early death }\end{array}$ & 0 & 0 & 17 & $\begin{array}{l}28 \\
17\end{array}$ & $\begin{array}{l}43 \\
24\end{array}$ & $25^{\star}$ \\
\hline \multicolumn{7}{|l|}{ Self reported practices } \\
\hline Thought $O K$ to sell if for parents & 2 & 10 & 38 & 37 & 37 & 37 \\
\hline Thought $O K$ to sell if for older sibling & 0 & 0 & 10 & 10 & 9 & 9 \\
\hline Thought $\mathrm{OK}$ to sell if nearly 18 & 0 & 0 & 15 & 14 & 8 & 8 \\
\hline Check ID or refuse sale if in doubt 18 & 20 & 100 & 74 & 70 & 76 & $75^{\star}$ \\
\hline
\end{tabular}

* $\mathrm{p}<0.05, \dagger \mathrm{p}<0.01$ for differences among store types, $\chi^{2}$ test.
RETAILER SELF REPORTED SALES PRACTICES

Retailers were asked in what circumstances they would sell cigarettes to minors. Seventy seven retailers $(33 \%$ ) said they thought it was alright to sell to minors if it was for their parents, $19(8 \%)$ for an older sibling, 23 $(10 \%)$ if the minor was nearly 18 , and nine $(4 \%)$ for other reasons.

Retailers were asked what they did if they have doubts about the purchaser's age. One hundred and fifty (64\%) said they would insist on seeing identification of age, 34 (14\%) would ask their age and accept what they were told, $30(13 \%)$ would refuse the sale, and $20(8 \%)$ would give them the benefit of the doubt.

RELATION BETWEEN SIZE OF STORE AND RETAILER KNOWLEDGE, ATTITUDES, AND SELF REPORTED PRACTICES

$\chi^{2}$ Analyses were used to determine whether there were differences in knowledge, attitudes, and self reported practices of retailers according to the size of the store. We classified stores into two categories: more than three employees who work in the store (large" store), or three or fewer employees ("small" store). The only difference between the two groups was on knowledge of the maximum fine. Smaller stores $(79 \%$ ) were more likely to know the maximum fine than larger stores $(66 \%)$ $\left(\chi^{2}=4.640, \mathrm{df}=1, \mathrm{p}<0.05\right)$.

\section{RELATION BETWEEN TYPE OF STORE AND}

RETAILER KNOWLEDGE, ATTITUDES, AND SELF REPORTED PRACTICES

Table 2 presents the knowledge, attitudes and self reported practices of retailers according to store type. There were three types of stores: supermarkets, small general stores, and small specialist stores such as newsagents and service stations. There were differences in knowledge and some attitudes among the three types of stores. Ninety nine percent of the specialist stores knew that the legal age was 18 compared with $93 \%$ of small general stores and $90 \%$ of supermarkets $\left(\chi^{2}=6.19, \mathrm{df}=2, \mathrm{p}<0.05\right)$. Only $61 \%$ of the specialist stores knew the maximum fine for illegal sales to minors, compared with $80 \%$ of supermarkets and $79 \%$ of general stores $\left(\chi^{2}=9.97, \mathrm{df}=2, \mathrm{p}<0.01\right)$.

Agreement with the 18 year old limit on sales differed by type of store $\left(\chi^{2}=8.70, \mathrm{df}=\right.$ 2 , p $<0.01$ ), with $64 \%$ of the specialist stores supporting it compared with $49 \%$ of general stores and $35 \%$ of supermarkets. Stores also differed in their perceptions of whether stricter enforcement would be effective in preventing underage sales of cigarettes $\left(\chi^{2}=8.11, \mathrm{df}=2\right.$, $\mathrm{p}<0.02)$. Supermarkets $(55 \%)$ and specialist stores $(43 \%)$ were more likely to think that stricter enforcement would be fairly to extremely effective compared with general stores $(28 \%)$. However, supermarkets $(0 \%)$ were less likely to believe that cigarettes were more likely than alcohol to lead to an early death than were small general stores $(17 \%)$ or specialist stores $(25 \%)\left(\chi^{2}=6.94, \mathrm{df}=2, \mathrm{p}<\right.$ 0.05). 
In terms of self reported practices, there was a trend indicating that supermarkets were less likely to think that it was alright to sell to underage adolescents if it was for their parents $(10 \%)$ than were general stores or specialist stores (both $37 \%)\left(\chi^{2}=5.722, \mathrm{df}=2, \mathrm{p}<\right.$ $0.06)$. Supermarkets were also more likely to say that they would ask for identification or refuse the sale if they doubted the age of the adolescent $(100 \%)$ compared with $70 \%$ of general stores and $75 \%$ of specialist stores $\left(\chi^{2}=7.86, \mathrm{df}=2, \mathrm{p}<0.05\right)$.

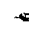

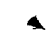

$<$

$\therefore<$

$+$

4

$\sim$

$-4$

$+$

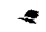

$\leq$

$\therefore$

3 visible activity by public health officers or police had been noted. The high proportion of retailers $(50 \%)$ who thought that those who broke the law should be prosecuted suggests that there is majority support for more effective enforcement activity.

When asked about the likely effectiveness of a range of smoking control strategies, nearly $40 \%$ of retailers thought that stricter enforcement of the laws was likely to be an effective strategy, along with banning or restricting vending machines, and restricting smoking in public places. It is of concern, however, that approximately $60 \%$ of retailers believed that stricter enforcement and restriction of vending machines would not effectively limit access of minors to cigarettes. This suggests a rather fatalistic attitude to the issue of access to cigarettes by minors. Such an attitude may be a result of a system in which no strict enforcement has taken place; therefore, retailers may have no means of knowing the effects of such enforcement efforts. It may also reflect the perception that minors have a number of other possible sources of supply such other retailers, peers, siblings, or even parents.

Our findings also suggest a poor overall commitment to ensuring adherence to the legislation. A strong indication of this poor commitment was the finding that $33 \%$ of retailers thought that it was acceptable to sell tobacco to minors if it was for their parents, $8 \%$ if it was for an older sibling, $10 \%$ if the minor was nearly 18 , and $4 \%$ for other reasons. One possible reason for the poor commitment towards strict observance of the sales to minors legislation may be poor knowledge about the health effects of smoking. Our study found that only $18 \%$ of retailers believed that cigarettes were more likely than alcohol or heroin to lead to an early death. Thus they seem to be largely unaware of the enormous toll that smoking takes on human life.

Various differences were observed in knowledge, attitudes, and self reported practices across types of retail store. These findings suggest that more work is needed to improve the attitudes and self reported practices of small general and specialist store retailers in particular. This is a special challenge, given the high turnover rate among ownership of small stores, particularly in the current economic climate. An ongoing programme of education and enforcement is required to ensure a high level of compliance with the law. ${ }^{12.17}$

The findings of this study have important implications for public health workers, because they suggest the need for a campaign to improve retailer knowledge of the health effects of smoking, retailer attitudes towards the sales to minors legislation, their perceptions of the legislation's enforceability, and the perceived likelihood of enforcement through a policy of active and consistent enforcement, as suggested by DiFranza. ${ }^{12}$ This will require an intersectoral approach involving public health workers, legislators, police, judiciary, public educators, and the mass media. There is a need 
to reverse the prevailing attitude that this is a low priority issue. International studies which have evaluated strong enforcement strategies such as local government legislation, giving powers for on the spot fines, and removal of tobacco licences for breaches of the legislation accompanied by strong educational campaigns have shown decreased rates of sales to minors and lower smoking rates among adolescents. ${ }^{17,18}$ Such a comprehensive approach to the implementation and enforcement of the sales to minors legislation is required in Australia to reduce the high uptake rates during adolescence and the long term burden of illness associated with adolescent uptake of smoking.

This research was undertaken by the New South Wales Cancer Council Cancer Education Research Program, directed by Prof R Sanson-Fisher. The views expressed are not necessarily those of the NSW Cancer Council. Grateful acknowledgment is made to Billie Bonevski for undertaking the interviews, to Lynne Kentish for statistical assistance, and to Charmaine Weeks for assistance with data collection.

1 Hill DJ, White VM, Gray NJ. Measures of tobacco smoking in Australia 1974-1986 by means of a standard method. Med F Aust 1988; 149:10-12.

2 Hill DJ, White VM, Williams RM, Gardner GJ. Tobacco and alcohol use among Australian secondary school and alcohol use among Australian secondary scho

3 Wakefield M, Carrangis J, Wilson D, Reynolds C. Illegal cigarette sales to children in South Australia. Tobacco Control 1992; 1: 114-7.

4 Sanson-Fisher RW, Schofield MJ, See M. Availability of cigarettes to minors. Aust $\mathcal{F}$ Public Health 1992; 16: $354-9$.

5 Altman DG, Foster V, Rasenick-Douss L, Tye JB. Reducing the illegal sale of cigarettes to minors. $\mathscr{f} A M A$ $1989 ; 261: 80-3$
6 DiFranza JR, Norwood BD, Garner DW, Tye JB Legislative efforts to protect children from tobacco. fAMA 1987; 257: 3387-9.

7 Hoppock KC, Houston TP. Availability of tobacco products to minors. $f$ Fam Pract $1990 ; 30: 174-6$.

8 Naidoo J, Platts C. Smoking prevention in Bristol: Getting maximum results using minimum resources. Health $E d u c$ f 1985 ; 44: 39-42.

9 US Centers for Disease Control Cigarette sales to minors - Colorado, 1989. MMWR 1991 ; 39: 794-5, 801.

10 Thomas B, Toffler WL. The illegal sale of cigarettes to minors in Oregon. $\mathcal{F}$ Fam Pract 1990; 31:206-8.

11 Schofield MJ, Weeks C, Sanson-Fisher RW. Alcohol sales to minors: a surrogate study. Prev Med 1994; 23: $827-31$

12 DiFranza JR. Active enforcement of minors' access laws: a moral and ethical imperative. Tobacco Control 1995; 4: 5 . 3 Chapman $S$. Reducing teenage access to cigarettes in Australia: time to act? Med f Aust 1993; 158: 219-20.

14 Davis RM. Reducing youth access to tobacco. $\mathcal{F} A M A 1991$; 266: 3186-8.

15 Biglan A, Henderson J, Humphreys D, et al. Mobilising positive enforcement to reduce youth access to tobacco. Tobacco Control $1995 ; 4: 42-8$.

16 Altman DG, Rasenick-Douss L, Foster V, Tye JB. Sustained effects of an educational program to reduce sales of cigarettes to minors. Am $\mathcal{f}$ Public Health 1991; 81: 891-3.

17 Jason LA, Peter JY, Anes MD, Birkhead SH. Active enforcement of cigarette control laws in the prevention of enforcement of cigarette control laws in the prevention of
cigarette sales to minors. $¥ A M A 1991 ; 266: 3159-61$.

18 Feighery E, Altman DG, Schaffer G. The effects of Feighery E, Altman DG, Schaffer G. The effects of sales to minors. $\mathcal{F} A M A 1991 ; 266: 3168-71$.

19 Breslow L. Control of cigarette smoking from a public policy perspective. Annu Rev Public Health 1982; 3 : 129-51.

20 NSW Health Department Report: Tobacco and health strategy, March 1993.

21 NSW Tobacco Advertising Prohibition Act (1991), No 65. 22 NSW Public Health Act (1991), No 10.

23 Andrews B, McKay L. Little Boxes, Little Boxes (and they're all made out of ticky tacky ...). Westlink, Autumn: 4-7. [Health Promotion Unit, Dept of Health, Dubbo.] 24 Carruthers S, McDonald C. The availability of cigarettes to minors in Perth, Western Australia. Tobacco Control $1995 ; 4: 49-52$.

25 Russell MAH. The nicotine addiction trap: a 40-year sentence for four cigarettes. $B r \mathcal{F}$ Addict 1990; 85: 293-300.

featuring articles on:

Trends and Effects of Smoking in Women * Adolescent Smoking * History of Women and Smoking * Smoking and Reproductive Outcome * Women, Tobacco and Public Policy * Smoking Cessation in Women * The FDA's Role in Tobacco Control * Cessation Techniqes * Tobacco Advertising Practices * Nicotine Addiction in the Context of Other Addictions * Legal Solutions to the Problem of Women's Smoking * The Physician's Role in Combatting Smoking and more...

$\square \$ 12$ for Women and Smoking

$\square \$ 50$ for a 1 -year nonmember subscription

\$55 for a 1-year foreign subscription
NAME

ADDRESS

CITY STATE/ZIP

Make checks payable to American Medical Women's Association and mail to: JAMWA, 801 North Fairfax Street, Alexandria, VA, 22314 (703) 838-0500 